\title{
The Dark God of Efficiency and the Economical Forms of Eladio Dieste
}

\author{
FEDERICO GARCIA LAMMERS \& JESSICA GARCIA FRITZ \\ South Dakota State University
}

"Efficiency is the dark god to whom we sacrifice so many things" 1

Since the rise of the Industrial Revolution in the 18th century, "innovation as progress" became a mantra of industrialized societies. As new materials and the methods for making them emerged, architectural education shifted from an École des Beaux-Arts education rooted in the principles of classicism to an arts and crafts based education definitive of the Bauhaus. This shift allowed architecture students the opportunity to work with new materials such as iron, steel, and reinforced concrete. Throughout the 20th century, innovations came less in the form of the methods that impacted material and construction and more in the form of representational tools. By the end of the century, digital tools dominated both architectural education and practice. In the last half of the 20th century Uruguayan engineer, Eladio Dieste recognized a representational fetish in architecture as he claimed that "current methods of construction and even our professional training teach us to do projects, not build buildings-we think more about the plans than the structure, or we only think about the structure through the framework of the plans." ${ }^{2}$ In his own practice, Dieste was able to collapse the space between representational and material knowledge by focusing on what he defined as Cosmic Economy. The first half of this paper will introduce the circumstances and methods associated with Dieste's practice in the context of Cosmic Economy. The second half of the paper will describe representation and construction processes as a means to exercise material knowledge in an ongoing student project at South Dakota State University.

\section{COSMIC ECONOMY}

Eladio Dieste did not fetishize innovation. His reinforced masonry work was focused on the development of structural ceramics through the role of Cosmic Economy. According to Dieste, Cosmic Economy was a means to understand that the "things that we build should be in accord with the profound order of the world." ${ }^{3}$

This definition may seem vague and in contemporary discourse could be a surrogate for sustainability. However, there is a pragmatic dimension to Dieste's definition of economy. In his definition, economy refers not only to the inherent cost of materials and construction, but also to the formulation of innovation through the relationship between a material and structural knowledge of that material. Dieste's idea of economy was separate from finances or the movement of money and its affects on architecture and construction. According to his former colleague, engineer Sasson, Dieste's "remarkable intuitions" in such projects as Church of Christ the Worker were framed by his interest in accelerating the construction process. ${ }^{4}$ This acceleration was initially tested to construct structural ceramic systems using steel reinforcement. Dieste's innovations in reinforced masonry can be seen in the form of self-supporting vaults, ruled surface walls, gaussian vaults, and folded plates.

In 1955 after collaborating with the Catalan architect Antoni Bonet on the Berlinghieri House, Dieste and Eugenio Montañez formed a partnership and began their own engineering practice. The start of the firm coincided with the start of one of Dieste's most iconic constructions, Church of Christ the Worker. The firm developed an unusual 
method of practice in the context of mid-century Uruguayan architecture, engineering and construction practices. Unlike many of their local contemporaries, such as engineer Mario Simetto, Dieste and Montañez S.A. was not only a calculation studio, but also a material and construction lab that operated as a design and build contractor. During this time Dieste was also faculty at the school of engineering in Montevideo teaching statics and structural mechanics. Dieste and Montañez S.A. is still open today and is run by one of Dieste's sons, Rafael, and the engineer Gonzalo Larrambere.

Since the completion of Church of Christ the Worker in Atlantida in 1961, Dieste's structures and his innovations in structural ceramics have become known throughout the world. Instead of marvelling at the audacity of his work, this paper proposes to examine the context and procedures that ran his practice, which in fact is what made these inspiring structures possible. Instead of focusing on strict calculations or Dieste's remarkable structural intuitions, this paper will focus on the framework through which his technological thinking can have resonance in teaching and practicing architecture.

In a number of contemporary architectural practices and in academia, the idea of economy has been telescoped into the role of sustainability or dismissed as "real world" financial constraints. In a post-industrial context, one way to fill the gap between teaching and professional practice is to ask for the hyper-specialization of professional knowledge to include a sense of Cosmic Economy inseparable from both the materiality of construction and its representation.

\section{CALCULATED INTUITION}

The notion of Cosmic Economy is fundamentally tied to the seemingly boring relationship among construction technology, labor, and ingenuity. The onset of the Industrial Revolution in the 18th century made the selection of building materials highly competitive and tied to the political realities of time and place. Building methods transitioned from assemblies based in masonry and wood to include newly developed and industrialized materials such as reinforced concrete. While previous building methods had relied on trial and error, after the industrial revolution engineers had at their disposal building methods that could be measured and calculated with precision, rather than by trial and error. ${ }^{5}$ This shift affected the selection of building materials throughout the construction industry and specifically impacted the work of Eladio Dieste. This impact is evident in many of Dieste's writings:

For architecture to be truly constructed, the materials should not be used without a deep respect for their essence and consequently for their possibilities. This is the only way that what we build will have the cosmic economy that we spoke of, and this cosmic economy is what sustains the world. When we use materials with this profound respect, we must be modest and be careful of our own aesthetic refinement. ${ }^{6}$

According to Gustavo Scheps, architect and dean of the School of Architecture in Montevideo, the role of the modernist project in Uruguay can be divided in two parts. ${ }^{7}$ The first half of the 20th century saw the development and proposal of the policies of president Jose Batlle y Ordoñez, later know as Batllismo. The social and economic reforms of 1916 led to specific social conditions that affected the architecture of Dieste through the centralization of resources and intellect in the in the capital of Uruguay, Montevideo. This moment in the history of Uruguay was capped by the visit of LeCorbusier in 1928 and the commitment to modernism as the primary vehicle for the improvement of society.

In the second half of the 20th century, the modernist project expanded to include and solidify a range of public infrastructure, such as coastal public works, like La Rambla, which is a continuous $35 \mathrm{~km}$ walk and driveway that stretches along the edge of El Rio de la Plata. Regardless of the prosperity experienced during the first five decades of the 20th century, Uruguay never expanded into a major manufacturing economy like that of its neighbors, Argentina and Brazil. More importantly, in the 1950s, the Uruguayan state began to consolidate as a vehicle for technological and infrastructural development. When Dieste developed his work, Uruguay was not a large manufacturing nation, the post-war manufacturing boom that saw the Argentinian and Brazilian economy grow and become important characters in worldwide modernism simply did not exist in Uruguay. Uruguay had the particular circumstance of being a very small nation of educated immigrants with limited physical and material resources. ${ }^{8}$ This is the context in which Eladio Dieste used structural ceramics to compete against other industrial materials such as reinforced concrete. His experiments in structural ceramics were not born out of nostalgia for brick, but out of competition and a simultaneously intuitive and highly calculated sense of materiality and structure. In Dieste's opinion the use of reinforced concrete in Uruguay was not economically sound because it required substantial external material efforts coming into the country in the form of portland cement and steel.

Dieste had the capacity to be at once philosophical and ethereal in his description of construction, as well as mechanical and pragmatic in his use of masonry. He does not speak directly about masonry, but rather filters his writings through the materiality of brick and its role in structural ceramics. One of the reasons for this is that Dieste's engineering education was primarily based in the study of reinforced concrete, which was the most advanced material technology of the time. His collaboration with Antoni Bonet suggested that he was not very familiar with the thin shell brick Catalan vault construction system. Instead Dieste chose to adapt an abundant local resource, brick, to a construction method that was more commonly associated with reinforced concrete. He did not invent the use of brick reinforcement and he is clear in his articulation that the only degree of invention he feels comfortable half-claiming has to do with the relationship among geometry, material and technique.

It is important to point out that although Dieste did not write very much, Architecture and Construction, Awareness of Form, and Art, People and Technocracy are his most compelling and revealing writings. It is in these three pieces of writing that he discusses the role of Cosmic Economy. In Art, People and Technocracy he is at his most political when questioning the definition of progress against the 


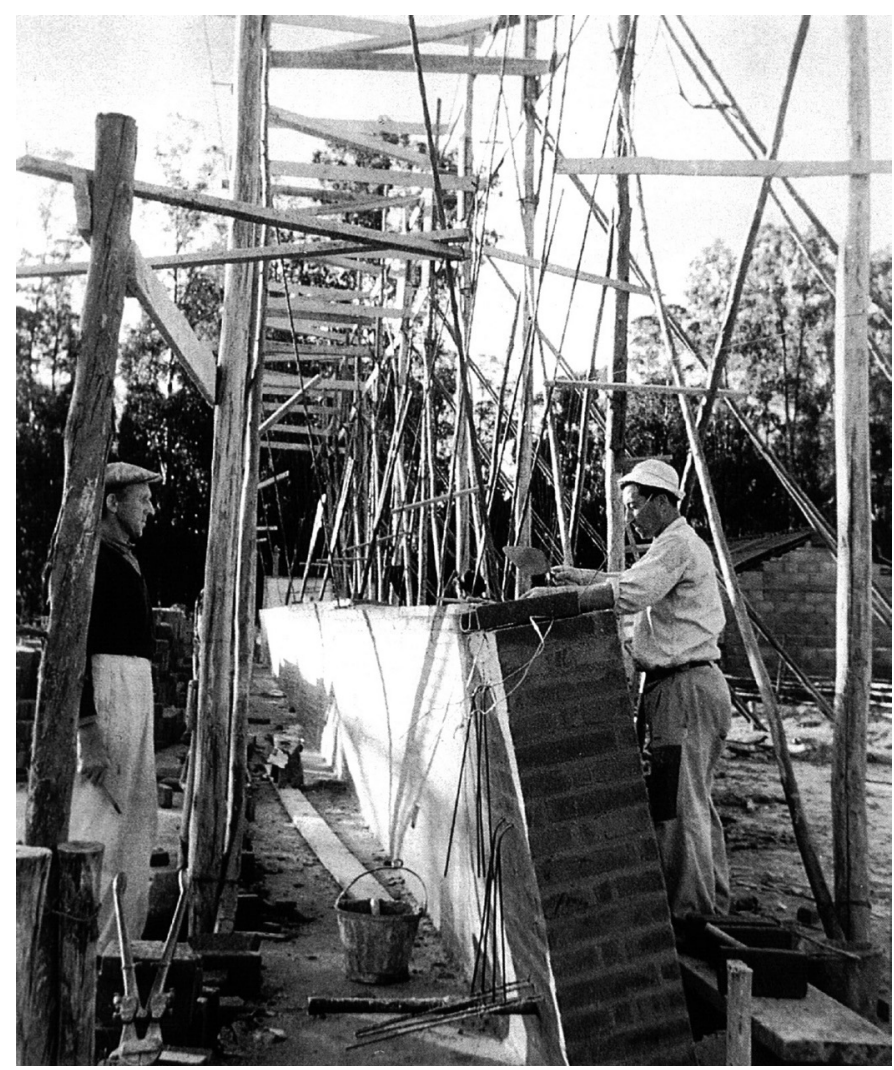

Figure 1: Construction of ruled surface walls at Church of Christ the Worker in Atlántida, Uruguay. Image from Dieste Archive published in Remo Pedreschi's, The Engineer's Contribution to Contemporary Architecture.

advancement of society through the purchasing of technology that is incompatible with the local resources of that country. It is in this writing that Dieste reinforces the claim that "architecture is also construction" and that the builder is an indispensable figure.

\section{COLLABORATIVE FRAMEWORK}

The work of Eladio Dieste was focused on a collaborative framework based on the authorship of construction processes. There are two sets of relationships that were fundamental to his Cosmic Economy and the development of these construction processes. The first is the role of labor and site management associated with the workflows of specific structural ceramics and reinforced masonry technology. The second was the collaboration between Dieste and Montañez S.A. with local fabricators.

During Dieste and Montañez's most active period labor-intensive work was seen as an economic and social good in Uruguay. This is important because it challenges the very notion of progress that has evolved with the neo-liberalist project in Uruguay and many other countries in the Americas. Dieste's buildings were coordinated by a job captain, who was not an engineer or architect. For the first thirty years of the firm there were three job captains that Dieste relied upon heavily: Vittorio Vergalito, Vito Pacheco, and Alberto Hernandez. Each of these men worked with Dieste for over thirty years. Job captains like Vergalito were responsible for articulating construction processes to the workers on site (Figure 1). These men were the means through which the ingenuity of Dieste's innovations became materialized through the combination of construction technology and labor.

This is fundamental to Cosmic Economy because it is an example of how collaborative processes can subvert the idea that industrialized efficiency is exclusively tied to impersonal methods of standardization. Instead these relationships propose a collaborative method that reinforces familiarity not only through material, but also through communication and its affect on the relationship between labor and construction technology.

Unlike many of his international contemporaries, such as Felix Candela or Frei Otto, Dieste derived his structures and forms exclusively through non-graphical calculations. Regardless of scale or scope, Dieste did not practice the form-finding methods of predecessors such as Antoni Gaudí. The economy of his forms were the product of numerical calculations intended to reach the most efficient structural equilibrium by establishing resistance through form and avoiding the "awkward accumulation of matter". ${ }^{9}$

The study of models is possible, but in general it is necessary to understand that these models will give us qualitative orientation. In order to make our efforts more quantitatively systematic, we will have to define and study the problem to achieve sufficient precision. In addition, the model is slower and more expensive than computation. I see it as a final step in very complex structures. In my building experience, I have used models very little. Whenever I thought about using it, I had, by that time, studied the problem so much that it wasn't necessary. What I can say is that the smaller structures have been the models for the larger ones. ${ }^{10}$

Eladio Dieste never made images of forms or projected visualizations of his work. If the primary method of developing form was through numerical calculations, then the primary means of describing these forms was the design of formwork. This is the method through which Dieste gave the intellectualization of construction and materiality priority over the manipulation of form. This gave way to a very important collaboration evidenced and documented in many formwork drawings and was ultimately seen in the construction of buildings throughout Uruguay, and in some cases Argentina and Brazil. The collaboration with Heinz Striew from the Francisco Suttener metal shop in Uruguay was fundamental to the means through which the formwork and its mechanisms were designed and fabricated. In addition, Dieste's collaboration with Striew resulted in the development of prestressing patents and other construction technologies. ${ }^{11}$ This collaboration was one of necessity, because importing patented adjustable mechanisms to use as part of formwork was simply not affordable, both in a financial and cosmic sense.

The continuous development of technology out of necessity and the ability to communicate this austere approach to other people involved in the construction was a key part of Dieste's practice. From the worker on site and to the person designing and fabricating the steel reinforcement in the vault or wall, coordinating the exchange of information was fundamental. 

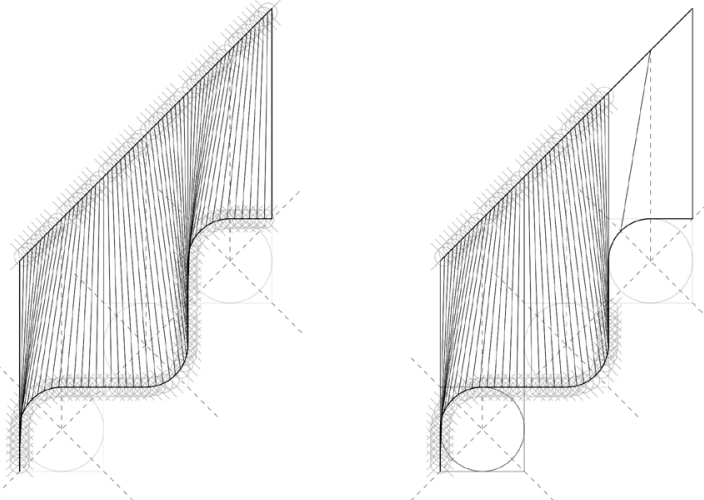

Figure 2: Ruled surface drawings, Curved Walls: Eladio Dieste and Ruled Surfaces Workshop, South Dakota State University.

\section{BUILDING WORKSHOP}

The Department of Architecture (DoArch) at South Dakota State University was started in the fall of 2010 and is the first professional architecture program in the history of the state of South Dakota. Since the start of the program one of the pedagogical focuses at DoArch has been to intersect the history of construction with collaborative acts of building.

In the spring of 2016 students at DoArch collaborated on the construction of a ruled surface brick wall as part of a building workshop titled, Curved Walls: Eladio Dieste and Ruled Surfaces. The sequence of undergraduate and graduate building workshops are focused on a haptic approach to the exploration of construction technology. Over the past four years building workshops have become a place where faculty research is injected into the development of faculty initiated student collaborations. More importantly, these workshops propose methods of work that prioritize the exploration of collaborative construction technology over the development of individual design projects. Building workshops are a venue in which students and faculty can intellectualize the act of construction.

In the aforementioned building workshop, fifteen undergraduate students met once a week for two hours throughout a fifteen week long semester. The class consisted of second, third, and fourth year architecture students. The workshop was designed to introduce students to Eladio Dieste's work through the combination of his writings with the preparation and execution of the construction of a ruled surface brick wall. The principal objective
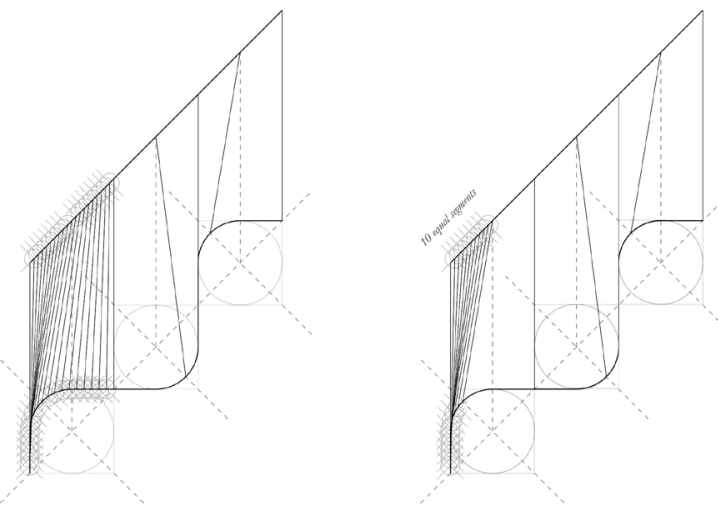

for the course was to unfold the implications of Cosmic Economy in a controlled academic construction setting. Additional objectives were as follows:

- Demonstrate an understanding of ruled surface geometry.

- Develop productive workflows, hand-drawing to 3D modeling and 3D printing.

- Author and document methods of collaborative brick masonry construction processes.

As discussed in the previous portions of this paper, Eladio Dieste did not write much. However, his writings offer direct insight into his technological thinking and the manifestation of this thinking into built form - a substantial teaching tool. Throughout the semester students continuously read Dieste's primary writings, which became a means to enter into a direct conversation with construction history. For the majority of the students this was the first time they came into contact with Eladio Dieste's work. More importantly, in spite of being very familiar with brick buildings, not a single student had ever laid a single brick for a wall.

Within the first two weeks it became apparent that Dieste's work was defamiliarizing the relationship many students had with brick as a material. This defamiliarization was prompted by the simple idea "that it is not enough to use brick because we like its texture and the fact that it is a material full of historical references. It is not that this is bad in and of itself, but we can take much better advantage of its possibilities. In this sense the current risks are much greater than before because modern technology apparently gives us the possibility of doing anything, of realizing any fantasy. It seems as if we can use construction materials as the set designer uses cardboard. The economic risks that this infers are not necessarily immediately visible, especially in the richer developed 

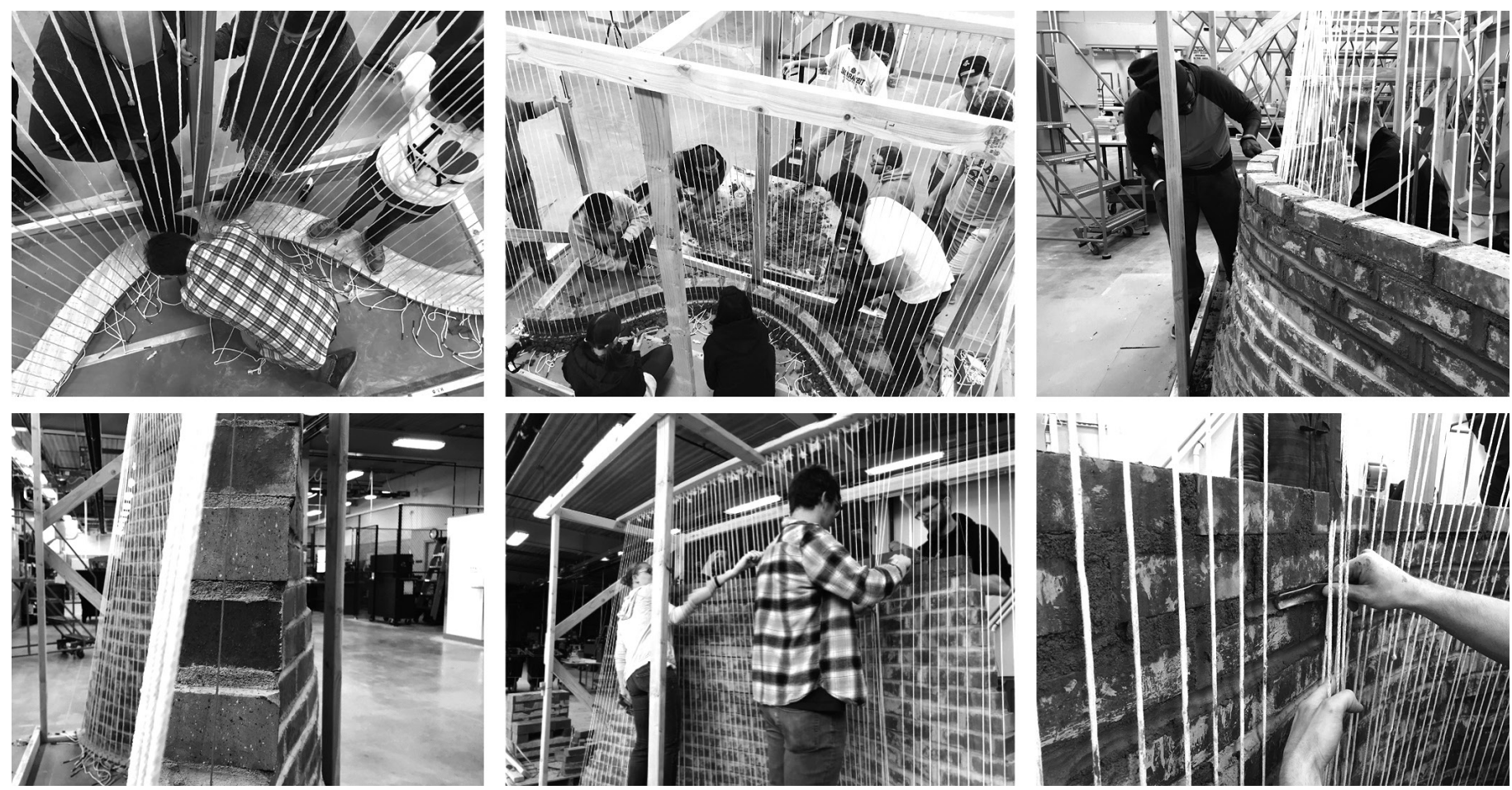

Figure 3: Ruled surface brick wall construction, Curved Walls: Eladio Dieste and Ruled Surfaces Workshop, South Dakota State University.

countries." 12 It was in these lines that the first weeks of the course began to resonate around the notion of Cosmic Economy.

\section{CURVED WALLS OR RULED SURFACES}

Throughout much of their professional education architecture students are taught to develop, validate, and communicate many of their ideas through drawings and models, analog and digital. The intersection between representation and making is one of the places of continuous contention between the academy and the profession. According to Dieste an approach to making that is initiated and verified by modelled or drawn representation is one of the reasons why most contemporary architecture in post-industrial countries seems to be assembled rather than built. In fact, much of this architecture is made possible by the assembly of discrete pieces rather than maximizing the economic potential of a specific material, making it apparent that "there are great architectural works in which you sense this weakness. They are not constructed, they have something that makes them seem like scenography." 13

The doubly curved forms of Dieste's work are one of the most easily recognizable elements of his architecture. Wether it is the ruled surface walls of the Montevideo Shopping Center or the Gaussian Vaults of the Don Bosco Gymnasium, students are drawn to the curved expression of his forms. This interest is even more relevant as students have developed an ease with digital construction and the physical assembly of complex geometries.

As mentioned, in the context of this workshop, the idea of curved surfaces was focused on the study of ruled surface walls. Students examined this geometry and learned the particular rationalization of this type of curve. A ruled surface is a curved geometry defined by a series of vertical lines, one of the most simple or familiar being a cylinder or cone. In Dieste's case ruled surfaces are directly tied to a sense of Cosmic Economy that pushes against the "technological dominance of the plane". For Dieste, a planar wall is simply not the most intelligent way of resisting the forces of gravity or the most economic way of using material. The curved forms and use of steel reinforcement in ruled surface walls allowed the height of the walls to grow while increasing the lateral stability and load baring capacity of these walls - simultaneously reducing the amount of material used in construction. The idea that building curved walls, or rather ruled surfaces, is a rational and intelligent way of constructing walls served to further defamiliarize students from the wall itself.

According to Dieste one of the reasons why planar structural systems exerted their dominance over the modernist movement was because they were easy to draw. This ease of drawing was matched by the ease of verifiable calculation and proof of structural performance discussed in the first half of this paper.

Throughout the entire semester students did not represent the form of the wall, but rather always worked on the definition of geometry through a series of ruled surface drawings and models. Students did not make a single drawing of the actual wall, or the bricks in the wall. The first set of ruled surface drawings were measured and constructed by hand, using a series of vertical lines to define the doubly curved surface (Figure 2). This exercise was intended to remove the ease of use through which students think about the representation of curved geometries, and reaffirm that very often the most economical forms are resistant to simple analysis. Subsequent drawings and models introduced computational means through which to define 


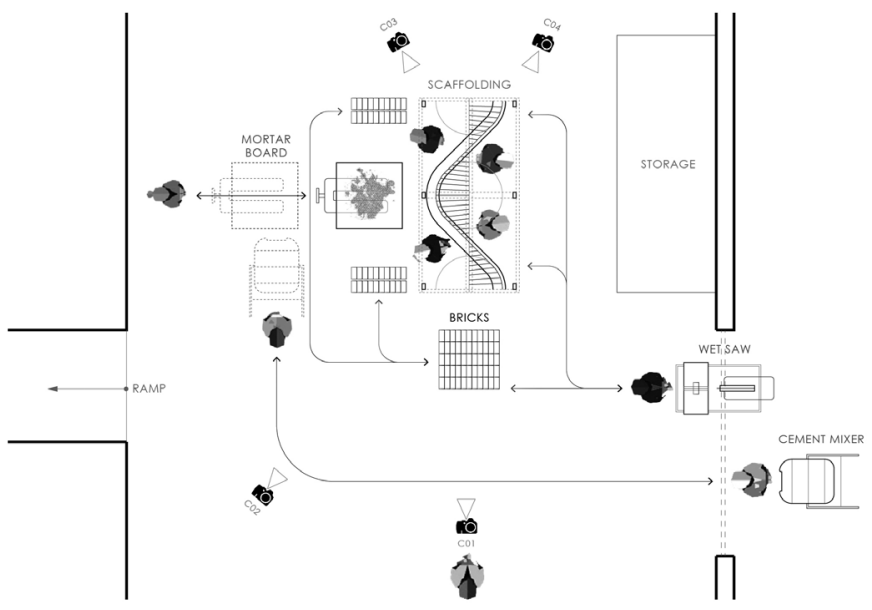

Figure 4: Construction workflow diagram. Curved Walls: Eladio Dieste and Ruled Surfaces Workshop, South Dakota State University.

and interrogate the representation of ruled surfaces. Through each method students worked on the definition of geometry anticipating the construction of the wall.

\section{AUTHORSHIP OF PROCESSES}

During the last five weeks of the semester students were prompted to author a construction process for building a ruled surface brick wall (Figure 3). All previous methods of work, reading, drawing, and modelling, were analogous to the act of the construction of the wall. In spite of not prototyping or making graphic representations of the wall, the knowledge transfer associated with the doubly curved geometry of a ruled surface had already taken place. The most difficult aspects of this portion of the semester had nothing to do with the geometry of the wall, but rather with the communication and design of structured workflows between fifteen individuals.

Establishing an economical workflow was primarily framed by the development of a detailed wall log and accompanying diagrams that documented each student's participation for five weeks (Figure 4). Prior to establishing this log students set clear roles and teams that defined the number of people working on the wall at one time and their respective roles. For example, the brick laying team consisted of two pairs of students. Each pair had one brick layer and one leveler/scraper. Another pair of students prepared and supplied the mortar during the construction sequence, while a single student measured and cut any irregular sized bricks. Meanwhile another pair of students was responsible for documenting the process and providing feedback or suggestions. Throughout the construction process, students changed roles purposefully and often. This method is not meant to simulate a Dieste construction site, but rather to reject a shallow sense of efficiency in favor of a deep sense of economy, an economy in which students are tasked not only with the documentation of the process, but also with the interrogation of the relationships that are formed as construction unfolds.
Ultimately students discovered that the ruled surface wall was the physical construction of a network of errors, which they could measure and evaluate. After three weeks of work we could assess if this network of errors undermined the geometry of the wall and its structural capacity. More importantly, students reflected on how the collective authorship of a construction process could unfold without making a single construction drawing.

\section{DISTORTED GOALS}

In a post industrial context, the end of much technology is profit, not utility, and profit is a measure of success most widely accounted for through the role of efficiency. How does efficiency distort the goals of architecture? This is primarily a question of how we value the concept of efficiency in the context of Cosmic Economy.

In teaching and practicing architecture, efficiency is deeply tied to the relationship between material and labor; one addresses the physical matter of construction while the latter deals with time. This is one of the most difficult aspects of teaching because in the last ten years we have entered a moment in which the ease of use of technology through representation makes the development of efficiency a largely unconscious thought. Simply because it is embedded into many representational and fabrication processes, but not necessarily authored by students or faculty. On the other hand, if we look for ways to simply resist the flow of new technology, there will be no articulation of potential invention. More importantly if we think of Cosmic Economy, then we should acknowledge that if there are technological advances without social advance, then in Dieste's words, "efficiency will continue to be the dark god to whom we sacrifice so many things".

\section{ENDNOTES}

1. Dieste, Eladio. "Architecture and Construction", in Eladio Dieste: Innovation in Structural Art, ed. by Stanford Anderson, (New York: Princeton Architectural Press, 2004), 189.

2. Dieste, "Architecture and Construction," 183.

3. Ibid. 186.

4. Silvestri, Graciela. "Una Biografía Uruguaya", Escritos sobre arquitectura: Eladio Dieste, (Montevideo: Irrupciones Grupo, 2011), 133.

5. Dieste, "Architecture and Construction," 188.

6. Ibid. 187.

7. Scheps, Gustavo. "Uruguay" in Latin America in Construction: Architecture 19551980, ed by Barry Bergdoll, Carlos Eduardo Comas, Jorge Fransisco Liernur, Patricio del Real, (New York: The Museum of Modern Art, 2015), 260.

8. Pedreschi, Remo. The Engineer's Contribution to Contemporary Architecture, (London: Thomas Telford Publishing, 2000), 12.

9. Dieste, "Architecture and Construction," 185.

10. Ibid. 185

11. Pedreschi, The Engineer's Contribution to Contemporary Architecture, 20.

12. Dieste, "Architecture and Construction," 187.

13. Dieste, "Architecture and Construction," 188. 


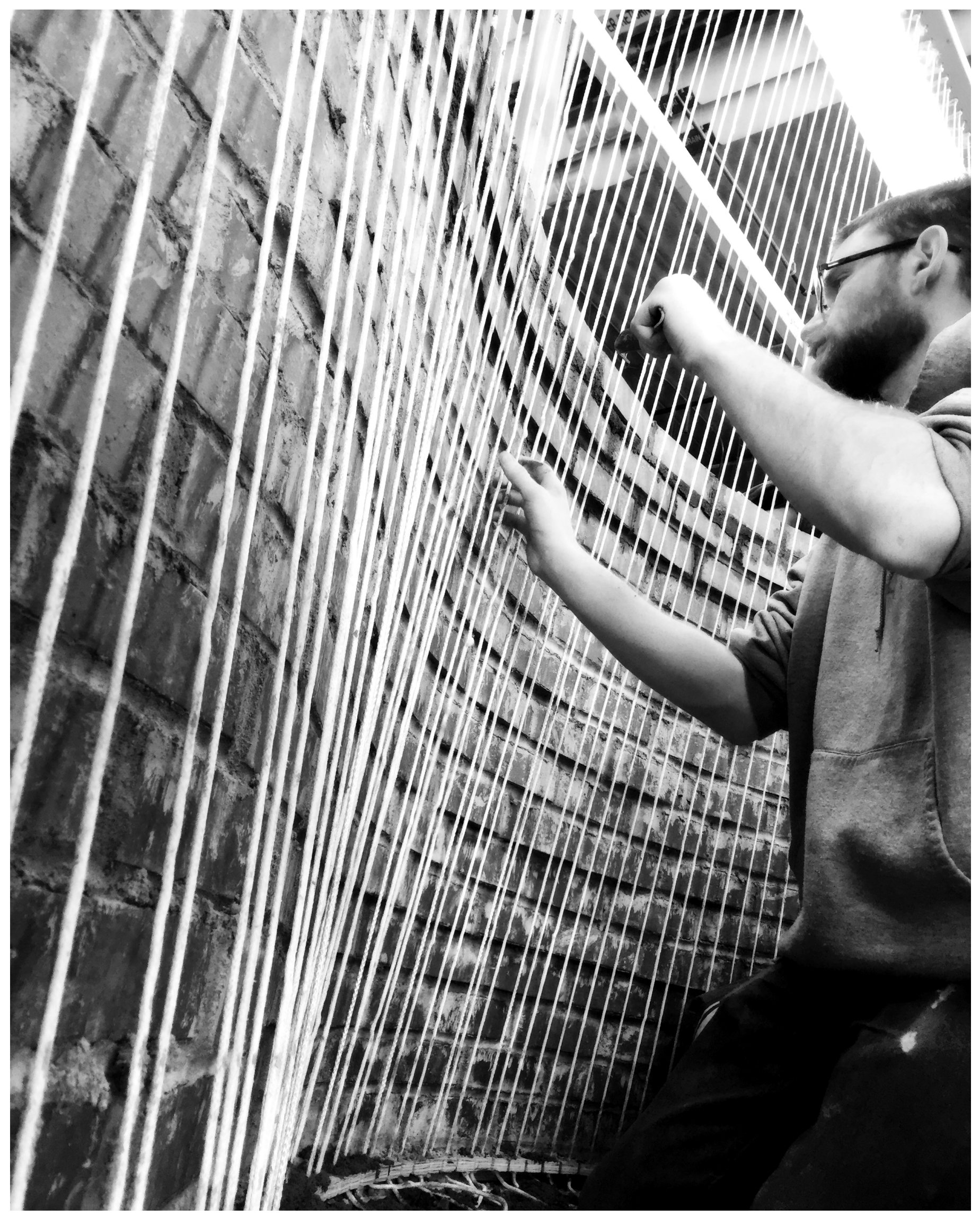

Figure 5: Ruled surface brick wall construction. Curved Walls: Eladio Dieste

and Ruled Surfaces Workshop, South Dakota State University. 